\title{
Relative abundance of insect predators varies among rice plots as a function of surrounding landscape
}

Md. Panna Ali ${ }^{1 *}$, Mir Md. Moniruzzaman Kabir ${ }^{1}$, Sheikh Shamiul Haque ${ }^{1}$, Abeer Hashem, and Elsayed Fathi Abd_Allah ${ }^{5}$

${ }^{1}$ Entomology Division, Bangladesh Rice Research Institute, Gazipur-1701, Bangladesh.

${ }^{2}$ Genetic and Plant Breeding Division, Bangladesh Rice Research Institute, Gazipur-1701, Bangladesh. ${ }^{3}$ Botany and Microbiology Department, College of Science, King Saud University, P.O. Box. 2460 Riyadh 11451, Saudi Arabia. ${ }^{4}$ Mycology and Plant Disease Survey Department, Plant Pathology Research Institute, Agriculture Research Center, Giza, Egypt. ${ }^{5}$ Plant Production Department, College of Food and Agricultural Sciences, King Saud University, P.O. Box. 2460 Riyadh 11451, Saudi Arabia.

"Corresponding author email address: panna_ali@yahoo.com

Abstract

Relationships among the population abundance of four predator groups for rice insect pests, namely: carabid beetles, staphylinid beetles, green mirid bugs, and spiders in three landscape categories were evaluated. Both rice plots and the associated bund margins of these rice plots found among three Bangladesh landscape categories were sampled by sweep net. The results revealed that the abundance significantly varied across landscapes. The rice landscape of one location harbored higher numbers of a specific predator than other location in other regions of Bangladesh. The results also showed a dependency on the width of the rice bund margins of the rice plots, where spiders populations increased with increased bund widths, but the population abundance of these predators did not depend on the diversity of the number of weed species found on the rice bund margins. The relative abundance of predator populations also significantly differed among the three landscapes, with the green mirid bug having the highest number among the four predators. This study indicates that predators of rice insect pests are highly landscape specific. In order to design integrated pest management systems for different Bangladeshi rice production locales, considerations unique to the characteristics of each locale are necessary. Preliminary efforts to apply variography analyses to the RED spectral band of LANDSAT 8 imagery from December 2016 are presented as first step 
34 toward learning a suite of methods which describe useful local characteristics affecting rice 35 pest predators.

36 Keywords: Rice landscape, natural enemies, location, population dynamics, variography, LANDSAT 8

\section{Introduction}

Rice (Oryza sativa L.), the staple diet of over half of the world's population, is grown on over 158 million hectares worldwide, which produced over 465 million tons in 2012. In Bangladesh, rice occupies about $77 \%$ of the cropped areas (Bhuiyan et al. 2004) which account for a total 11.6 million hectares to produce 34 million tons of milled rice (IRRI, 2014). Bangladesh has 3 rice growing seasons (BRRI, 2016); namely, Aus (monsoon rice), Aman (rain-fed with supplemental irrigation) that has two types of production (Broadcasted Aman and Transplanted Aman), and the Boro (irrigated and well managed rice) season. Rice is cultivated throughout the year and the intensity of cultivation increases day by day to meet demands from more people living in Bangladesh every year. The rice agro-ecosystem covers the major part of the non-urban land area in Bangladesh. These rice eco-systems are inhabited by hundreds of arthropod species (Heong 2011) which perform various ecological functions, such as herbivory (feeding on the rice plants), predation, parasitization, pollination, decomposition, and nutrient cycling.

To date, 232 rice insect pests and 375 beneficial arthropod species have been identified from the rice ecosystem in Bangladesh (Ali et al., 2017). However, while fewer than 20 species are of significance in causing yield losses when they occur in sufficiently large numbers in India, Bangladesh, numbers up to 20-33 total species considered of

57 importance to cause economic damage to rice production (BRRI, 2007). These pests, in turn, are subjected to attack by predators and parasitoids, and thus, are often naturally kept in 
59 check. This intricate food web of relationships among the rice plants, the pests, and the rich

60

61

62 biodiversity of natural enemies constantly strives to maintain an equilibrium preventing abnormal increases in abundance of pest species. This equilibrium level of a rice ecosystem is also often broken due to heavy use of synthetic fertilizers and pesticides. The breakdown in 'ecological resilience' of a rice farm induces pest's outbreaks (IRRI, 2011) that causes economic damage to rice growers worldwide, despite usage of insecticides.

Scientists have long claimed that indiscriminate use of pesticide is the main reason for major outbreaks of insect pests in many kinds of crop production plots (Stern et al., 1959). A recent example in rice is the increase in outbreak frequency of Nilaparvata lugens (brown planthopper) over numerous Asian rice growing countries in recent years, 2005-2012 (Heong, 2010), due to adverse effects on planthopper natural enemies (NE) caused by increased use of broad spectrum insecticides for control of other kinds of rice pests (Chien and Cuong, 2009, Heong, 2009, Islam and Haque, 2009, Moni, 2011;2012, Luecha, 2010, Matsumura and Sanada-Morimura, 2010, Soitong and Sriratanasak, 2012, Teo, 2011). The use of pesticides increased in Bangladesh by $200 \%$ from $1997-2000,250 \%$ by 2006 and by nearly 500\% by 2014 (BPCA, 2015). More than half of the amount of those insecticides was applied against rice pests. Synthetic chemical-like insecticides are hazardous and harmful for non-target organisms (e.g., Travisi et al., 2006, Ahmed et al., 2002; 2011). Besides just the increasing usage of chemical insecticides over the years, other factors such as climate change and landscape change also induce disappearance of NE from Bangladesh rice plots. Analysis of

Natural enemies abundance in a crop plot vary with the apportionate areas of different habitats that prevail in the surrounding landscape (Bianchi et al., 2006; Werling et al., 2011) and possibly with differences in small scale changes in timing and choice of management decisions (Willers et al. 2005; Shaw and Willers, 2006) for another insect pest, such as Lygus 
84 lineolaris in Mid-South, USA, cotton. Landscape changes, which shape the habitat structure, materials, and biotic interactions in agroecosystems, are also important factors driving pest and NE population abundance (Woltz et al. 2012). Landscape characteristics can influence pest and NE population in crop field. Recently, remote sensing method provide quickly various types of surface monitoring data such as local, landscape, vegetation, specific crop, water body and animal population. Variogram analysis of the data for spatial heterogeneity can help identify explain related ecological phenomena (Zhaofei et al. 2013). Here we intend to use variogram analysis and find their impact on landscape characteristic which also can explain the pest and NE population abundance. It could also be used to improve quantitative agricultural remote sensing monitoring in a spatial heterogeneity area as well.

Examining such kinds of impacts on pests or NE and understanding their mechanisms may help to design pest management strategies at landscape scales (Wang et al. 2015). However, the description of the abundance of NE in different Bangladesh rice landscape categories remains elusive. Therefore, the objective of this study was to assess the abundance of NE in different rice landscapes to help design pest management strategies influenced by the different rice production seasons, types of production styles (i.e., small, household farmers vs large, non-household farmers) and categories of landscape-scale agro-ecosystems. In addition, variograms are used to analyze the landscape characterize based on LANDSAT 8 images collection. To target this objective we surveyed, recorded, and summarized the abundance of several NE species from different rice landscapes in Southern Bangladesh.

\section{Materials and Methods}

The sampling experiments were conducted in three categories of landscape located in Southern Bangladesh, or the Barisal Division, which includes within it the Barisal and Jhalkathi Districts, where each district is further divided into two more smaller governmental entities, known as the Upazila, and within these, the smallest one, known as a Union (Refer to 
109 Fig. 1, where all but the Upazila are mapped). Each landscape category represents a unique

110

111

112

113

114

115

116

117

118

119

120

121

122

123

124

125

126

127

128 type within several Unions of these two Districts, and which are sufficiently describable to permit replication (in geographic space at the Union designation) of each category. We defined these rice landscapes within a buffer zone around each one, into three category classes based on surrounding features and characteristics found within the buffer zone surrounding candidate rice plots. Each landscape was replicated two times.

Landscape I - Rice plots in this category are typically surrounded by big and small fruit trees, or forests (such as deciduous and coniferous trees). The entire rice plots, here, are enclosed by densely perennial habitats, having fewer kinds of annual crops and lower vegetational diversity. The perennial habitats are found in close proximity to rice plots, with an range of distances from 10-30 $\mathrm{m}$. The main feature of this landscape is the presence of small, narrow (so called canal), drainage flows between the rice plots and (concrete) roads, which always flows, and with some weeds growing in the canals. The canals are connected to rice plots, which were very muddy types. The irrigation system of this landscape is comprised of a shallow tube well. The width of rice bunds surrounding rice plot, are between $25-35 \mathrm{~cm}$ and separate one smallholder plot from another one. Landscape I replicates were selected near Protap, in the Rajapur Upazila Union, and the Jhalokathi Sadar Union of southern Bangladesh, and were of similar structure and composition by visual interpretations. The specific location of this landscape is presented in Fig. 1A.

Landscape II - This category consists of rice plots, homestead trees, and a rain forest, containing both small and big trees. The landscapes are located the Nalchity Upazila, in the Jhalkati and Barisal Sadar Unions of southern Bangladesh, characterized by less muddy rice plots found near roadsides, with a few fruit and forest trees found around the rice plots and planted along the roadside. Any nearby perennial habitats were very far from the rice plots, compared to Landscape I, with distances between 100-200 m. There are no canal or drainage 
systems in this landscape and the irrigation system is comprised of deep tube wells. The specific location of these landscape replicates is also shown in Fig. 1A.

Landscape III - This third category was selected near the Babuganj and Wazirpur Upazilas, and only from the Barisal District of southern Bangladesh, and is found with an irrigation system different from others. The specific locations of this landscape category replicate is depicted too in Fig. 1. Here, a buried irrigation system was used and the rice plots are surrounded by some local fruits and other cultivated trees, but slightly farther away from the rice plots. Any areas of perennial habitats were very far from the rice plots, with distances between $200-400 \mathrm{~m}$. The roads were also $200-400 \mathrm{~m}$ farther away from the rice plots than any roads if the other two landscape categories. Small, narrow trees were also found alongside the roads. A narrow small canal was also present in this landscape, but that canal was 300-400m away from the rice plots. Entire rice plots were divided into two separate, but big parts, by a wide walking bund, with an additional irrigation channel located on this bund.

Rice plots from each landscape selected for study ranged 15-20 ha in area. The total set of rice plots in each replicate was composed of 50-70 plots separated from each other by bunds in each sample location among the landscape categories, except for Landscape III. In the Landscapes I and II, each small plot was occupied by one smallholder rice farmer, whom maintained their plots according to improved rice production technology. The size of farmers plot ranged $1500-2500 \mathrm{~m}^{2}$. The plot size in Landscape III ranged between $1000-2000 \mathrm{~m}^{2}$, and were farmed by smallholder farmers. The 'plots' for all replicates selected to record arthropod populations was transplanted with BRRI dhan29 (a mega-rice variety in Bangladesh). Four-6 plots from each landscape were considered for data collection.

For transplanting BRRI dhan29 in selected rice plots, farmers raised seedlings in a seedbed. Seedbed management was performed according to the traditional farm practices (BRRI, 2011). Before transplanting seedlings into candidate sample plots, land was well 
159 prepared according to the common practice of wetland soil preparation followed by 160 laddering. Laddering is the cultural farming practices where the ladder is used to break down 161 clods and level the plot once or twice after ploughing. Thirty-five to $45 \mathrm{~d}$ old seedlings were 162 transplanted in selected rice plots during the Boro rice cultivation season in 2015-2016. 163 Standard transplanting space $\left(20 \times 20 \mathrm{~cm}^{2}\right)$ was maintained. Fertilizers containing N, P, K, and $\mathrm{S}$ were applied at the rates of $82,15,38,10.6$ and $2.7 \mathrm{kgha}^{-1}$ respectively, using urea, triple superphosphate (TSP), muriate of potash (MOP), and gypsum. The total amount of TSP, MOP, gypsum, and $1 / 3$ of the urea amount were applied during the final land preparation period. The remaining urea was top dressed in two equal splits at $20 \mathrm{~d}$ after transplanting (DAT) (or the early tillering stage) and 40 DAT (or the maximum tillering stage), synchronized with irrigation or wet soil conditions, because the sampling experiment was conducted under irrigation conditions. Pesticides were applied two times in all rice plots across the tested landscapes. Therefore similar amount of pesticides were received by each rice plot.

Arthropod populations were recorded from 4-6 plots of each replicated rice landscape category which means 24-36 plots (4-6 plots x 6 landscapes). Two landscapes of each category were considered for this study. The sampling was conducted two times. A sampled plot was randomly selected from the entire set of rice plots found, as present in a replicated landscape category. Arthropod populations were collected from both the chosen rice plot, and its adjoining rice bund, using a sweep net. Durable insect sweep nets easily collected insects from grass, fallow land, brush and the rice crops. Two times 20 complete sweeps were taken to collect insect pests and their NE at maximum tillering stage of the rice crop at each sample plot, because that stage of rice harbors a wider number of arthropods (Bari et al. 2016). The collected insect pests and NE were sorted, identified, counted and written onto a data collection sheet for every sampled plot. Each bund was covered by numerous weed species. 
species were not identified taxonomically, but instead to only estimate the total number of weed diversity, as found on that bund. The width of each rice bund was also recorded using a measuring scale. The plot used to collect arthropods using sweep net was also examined by rice hills (for a total of 100 hills/sampled rice plot), to make additional observations on infestations by insect pests that stay in the lower part of the plant. The sampled insect pests observed in the tested plots in each landscape were negligible and avoid to present in the paper. Therefore only NE populations were described here.

Relative abundance of NE populations was calculated using the following equation (Rahman et al. 2014):

$$
\text { Relative abundance }(\%)=\frac{\text { Total No. of individuals of each species }}{\text { Total No. of of individuals of all species }} \times 100
$$

Data were analyzed by means of analyses of variance (one-way ANOVA), using landscape category as the explanatory variable. Means were compared by Tukey's test among the landscapes $(\mathrm{P}<0.05)$. The paired $t$-test was also performed to analyze the effect between rice plot and bund. Data were transferred to logarithm scale in order to homogenize the variance. Pearson's correlation analysis was used to determine the correlation coefficients between NE populations with rice bund's width and number of weed species growing on the bund. All statistical analyses were done using SPSS software, Version 16.0.

A LANDSAT 8, true color satellite image in TIFF format, (labelled, LC08_L1TP_137044_20161130_20170317_01_T1) for late November, 2016, was obtained from the United States Geological Survey (USGS) website for variography analyses. It was hypothesized that variograms at the Union area extent of the 6 sampled landscapes and 12 more non-sampled, non-classed Unions for comparison, could be useful to aid in landscape classifications of the other Unions of the Barisal and Jhalkarti Districts of the Barisal 
210 ARCGIS $^{\circledR} 10.2$, and SAS ${ }^{\circledR}$ software for PROC VARIOGRAM were utilized to process and 211 analyze the RED spectral pixels contained within the polygon feature layer of the selected 212 Unions (Fig. 1). This date was selected for its cloud free characteristics and because it was 213 not closely associated with the sampling times of the plot survey data, in order to examine 214 how non-seasonal information from satellite platforms may aid the ground survey results and characterization of the sampled landscape classes.

\section{Results}

217 We have assessed four (4) different insect predators under the present study namely, spiders - a general predators group, the green mirid bug (GMB, Cyrtorhinus lividipennis Reuter) an egg predator of planthoppers and leafhoppers of rice, the carabid beetles $(\mathrm{CB})$ - predators of several kinds of planthoppers and leaffolder larvae of rice, and the staphylinid beetles (staphilinids) - a generalist predators of the nymphs of planthoppers. The number of insect pest species found was negligible during this phenological stage while sampling NE, having no effect on rice yields. The sampled plots (and plots) were also tracked up to harvesting stage in order to detect if a significant number of pests occurred after data recording. The investigated plots did not show any visual plot damage due to insect pests. But the number of NE population varied among the landscapes and their population dynamic was described below.

Spider: Spiders were significantly different among the landscape categories recorded from the landscape I, landscape II and landscape III rice plots. The landscape I showed the highest population numbers than that of the other two categories (Fig. 2). Number were significantly higher in the rice (plot) plots than the rice bund in landscape I and landscape II, but the highest population was found in rice bunds in the landscape III (Fg. $2 ; p=0.001)$. The spider populations also depended on the width of rice bund and a trend of increase followed the 
235 width (Pearson's correlation, $r=0.576 ; p=0.050$ ), but there was no correlation between spider numbers and the number of weed species found in the bunds (Pearson's correlation, $r$ $=-0.119 ; p=0.80)$. The relative abundance of spider population also significantly differed among the different landscapes (Fig. 7).

239 Green mirid bug (GMB): Population of GMB was significantly different among the landscapes. Rice plots located in landscape I showed the highest populations compared to that of the other two (Fig. 4, $d f=9, F=167.58, p<0.001$ ), while the lowest population was observed in the rice plots of landscape III. Similar number of GMB population was found in the rice bund of both landscape I and landscape III and significantly less individuals were observed on the rice bunds of landscape II (Fig. $4, d f=9, p<0.05$ ). Populations of GMB differed significantly between rice plots and rice bund among all landscapes $(d f=9, p<$ 0.001). The relative abundance of GMB population also significantly differed among the different landscapes (Fig. 7).

Carabid beetles (CBB): Populations of CBB significantly varied among all landscapes, where landscape III showed the highest numbers in the rice plots than that of the other two landscapes (Fig. 5, $d f=9, F=167.58, p<0.001$ ), with the least found in landscape II. In regards to the rice bund, highest number of CBB population was found in landscape III and the lowest population was observed in landscape I. The CBB population significantly varied between rice plots and rice bund at every landscape $(d f=9, p<0.001)$. Like the spiders, the

254 CBB abundance also depended on the width of rice bund and increased with increased bund widths. Significant correlation existed between these two variables (Pearson's correlation, $r=$ 0.423; $p=0.050)$. No significant correlation existed between CBB numbers and number of weed species found on the bund (Pearson's correlation, $r=0.119 ; p=0.78$ ). The relative abundance of CBB also significantly differed among the different landscapes (Fig. 7). 
259 Staphylinid beetle: Landscape III contained significantly more staphylinids than landscapes 260 I and II. (Fig. 6, $d f=9, p<0.05$ ). The rice bund located in landscape III harbored the highest 261 number of staphylinids where the lowest population numbers occurred in Rotab. The 262 staphylinids varied significantly between rice plots and rice bund in landscape I ( $d f=9, p<$ $2630.05)$ but did not show so in the other two landscapes $(p>0.05)$. Staphylinid abundance in the rice bund did not depend on the width of the rice bund. No significant correlation existed between these two variables (Pearson's correlation, $r=0.322 ; p=0.481$ ). Also, no correlation existed between staphylinids and the number of weed species grown in rice bund (Pearson's correlation, $r=0.243 ; p=0.599$ ). The relative abundance of staphylinids also significantly differed among the different landscapes (Fig. 7).

Variography Analyses. Variography is a typical geostatistical procedure used in analyses of imagery (Stein et al., 2002). For the purposes of this research, however, the variograms derived by each Union, subsetting out only the RED pixel attribute for estimating the empirical variogram, used a RANGE parameter large enough to span the breadth of each Union, regardless of its size and shape. Hence, the variograms plotted show more undulation than most often found by other analysts, whom only seek to estimate a randge distance where the SILL parameter reaches its initial plateau (Fig. 8). To understand how variography of a large areal extent can related to landscape level characterizations, more liberty in the range attribute of each variogram of each of the six Unions was granted. Each union is designed as one landscape based on their surrounding characteristics. Variogram analysis on remote sensing data determine spatial heterogeneity, providing insight into interesting spatial characteristics of the crops and could be extend to multitemporal analyses (Zhaofei et al. 2013; Duveiller and Defourny 2010; Levin 1992).

\section{Discussion}

The presence of NE is a vital component of Integrated Pest Management (IPM) for control of the insect pests of any crop. In this sampling experiment we tried to quantify the 
285

286

287

288

289

290

291

292

293

294

295

296

297

298

299

300

301

302

303

304

305

306

307

308

309

310

311

312

313

314

315

316

317

318

natural enemy's abundance prevailing in three distinct rice landscapes. We found that the natural enemy's numbers varied significantly among the sampled landscapes. We took samples (Wang et al. 2015) from the three different locations and showed significant differences in natural enemy's abundance among the landscapes, and also, most times, between those found in the rice plots compared to the rice bund. We hypothesize that the variation in NE abundance among these landscapes arose due to environmental factors (such as, temperature, landscape elevations, historical plant communities, soil characteristics, weather forcings, etc) or anthropogenic factors (that is, cultural or pest management practices). At this stage of investigation, we cannot consider which one of a list of factors most influences the results of this study.

High abundance of GMB population was found in rice plots in landscape I located in Protap $(\mathrm{p}<0.01)$, but the host insect pest prey for GMBs were not found in those rice plots. The actual mechanism is unknown to explain why GMB population was so high in landscape I. Because preys of the GMB were absent in sampling plots though GMB population depends on prey populations such as BPH, WBPH etc. We also investigated prey individual using both sweeping and individual rice plants examined by naked eye (visual counting) to identify the prey numbers possibly found in the rice plots. Prey insect pests, especially the brown planthopper (BPH), the white-backed planthopper (WBPH), or the green leafhopper (GLH) were not found in any abundance among the landscapes. Generally, GMB eats eggs of BPH, WBPH, GLH laid in rice stems in plot plots. Here, we can assume that prey population could be very small due to huge number GMB population and prey numbers were so low that we could not measure damage to any rice plant at the sample number sizes we used. However variation of predator's populations can be explained by other ways. We hypothesize that landscape structures might provide the suitable hosting for specific predators that could induce higher number of predators in rice plot. Landscape-structures containing perennial habitats can support higher abundance of NE (Andow, 1991; Schmidt and Tscharntke, 2005) or natural enemy's population can be influenced by that vegetational diversity (Werling et al., 2011).

In our study landscape I contained abundant perennial habitat surrounded the rice plot (see methodology section). Therefore, landscape I showed higher number of GMB due to its abundant perennial habitat/ higher vegetational diversity (Bianchi et al., 2006; Werling and Gratton, 2008). A landscape may have a large proportion of semi-natural habitat and be otherwise dominated by a single semi-natural land-cover type such as forest. In this experiment, the presence of semi-natural habitat/ abundant perennial habitat was a better 
319 predictor of GMB abundance than habitat diversity (Bianchi et al. 2006). Moreover, we

320

321

322

323

324

325

326

327

328

329

330

331

332

333

334

335

336

337

338

339

340

341

342

343

344

345 proposed that aquatic weeds growing in narrow canal close to the landscape I rice plot harbored the mirid bug population. Pesticide also influences the natural enemies in rice field. However, all tested landscapes plots received similar amount of pesticide during the crop growth stage. Therefore, we can not explain that pesticide influenced the NE at tested rice plot.

Similarly, the highest number of spiders was found in Landscape I. Such may be due to the effect of landscape composition/ecosystem, including the surrounding environmental conditions. Higher numbers spiders were found in rice (plot) plots than the rice bund in both landscape I and landscape II, but in contrast lower numbers occurred in rice plots than the rice bund at the landscape III. Since the population numbers depended on rice bund width (Fig. 3), and the rice bunds were smaller in landscape I and landscape II (approx. $25 \mathrm{~cm}$ ) than in landscape III $(75-150 \mathrm{~cm}$, or 3-6 times wider), bund margins may be particularly important as a source of colonization by ground dispersing predators, such as large Pardosa pseudoannulata spiderlings and adults (Sigsgaard 2000). Wider space of rice bund host greater number of weeds species which too can induce higher numbers of spiders in landscape III bunds. But in our study we did not find any significant correlation between NE' populations and number of weed species grown in rice bund ( $\mathrm{df}=8, p>0.05$ ), so again, understanding of the mechanisms involved is naïve. More investigations are going to be necessary to increase understanding them.

The population of carabid beetles and staphylinid was higher at landscape III than Landscape I located at Protap. The variation might occur once again due to the effect of landscape characteristics, including surrounding environmental conditions or man-made traditions. Agricultural landscape producing existing and introducing new crops for mitigating nutritional secure and food security for additional people. These changes influence predators at local scales, as some crops might provide suitable/or unsuitable habitat than previous one (Maredia et al., 1992a; Bommarco, 1999; Landis et al., 2000). 
We also applied variogram model for describing the spatial relationship between neighboring locations which are the critical elements of any spatial distribution (Hershey 2000). The model is applied to match closely the spatial relationship observed in the sample data. In this report, the \%population/plot estimates of four predatory insects were further refined. Spider and mirid species, carabid beetle and staphylinid beetle varied by region, and the process of variogram modeling and estimation was repeated for each region. With mirid bug population, the region was applied to target more specifically those areas in which the species was more dominant. More too needs to be developed with respect to applications of variography, because our initial findings (Fig. 8) suggest that sets of graph pattern and shape can be derived. The need is for further collaboration between the expertise of the Bangladesh rice and Mid-South, USA cotton entomologists do further work of analyses of public domain imagery, not only over years, but of months within years, and different areal extents while also obtaining important count data of NE and pest abundances by on-the-ground sampling work. In addition to these kinds of data layers that relate the temporal resolution of the information, care must also be given to spatial and spectral resolutions of the remote sensing layers as available. Our early collaborations show opportunity for learning more about our various agriculturally distinct landscapes (and arthropod fauna of interest) to eventually accomplish the objective of this research.

\section{Conclusion}

In this study, landscape characteristics affected rice pest NE rather than prey population numbers. Surprisingly, we did not find any prey species of a most important predator, the GMB. At a local scale, NE' abundance increased within the managed habitats. Thus, among the different landscapes they were more often differently captured between the rice plots of plots than the plot edge habitat of the rice bund. In contrast, overall NE' levels in equivalent habitats may be related with proportional abundance of semi-natural, dominating, single 
371 habitat types found different within each landscape category. Predator individuals in rice

372 plots to landscape-scale semi-natural habitat was identified by the presence of adjacent

373 environmental components, indicating that for these predators, landscape characteristics

374 override the effect of enhanced local resources. This suggests that to manage for increased

375 bio-control services for rice insect pests will require a focus on manipulating overall

376 landscape structure. A greater understanding of these complex relationships will enable

377 growers and researchers to develop more effective management systems suited to specific

378 landscapes, prevailing pests, and their natural enemy communities. Thus, we may anticipate

379 that in the future a combination of local and landscape management practices may be

380 required to maximize overall pest suppression in these larger agro-ecosystems.

381

382 Conflict of interest

383 Authors declare that they have no conflict of interest.

384 Acknowledgement

385 We greatly appreciate Dr JF Willers for developing variogram model and preparation of 386 figure 8 reported in this paper. We also acknowledge those who (plot staff/assistants) helped 387 to record data and plot experiment and especially we acknowledge farmers for providing land 388 for this experiment. The authors would like to extend their sincere appreciation to the 389 Deanship of Scientific Research at king Saud University for its funding this Research Group 390 NO (RG-1435-014). 


\section{Figure caption}

399

Fig. 1: Map of the Southern part of Bangladesh, for the Barisal Division, where six unions

400 contained the three landscape categories (see text for listing) sampled for insects, while all

401 eighteen unions were employed for variography analyses.

402

Fig. 2: Abundance of spider in three rice landscapes. Means followed by the same letter do not differ significantly at 5\% level. The error bar represents the standard error. $(* * *, * *$ and $*$ indicate significant at $0.1 \%, 1 \%$ and $5 \%$ level respectively. Capital and small letters indicate the rice bund and rice plot in different landscapes respectively.)

Fig. 3: Effect of rice bund width on the spider individuals. Ten complete sweeps were used to record population from rice bund.

Fig. 4: Abundance of green mirid bug (GMB) in three rice landscapes. Means followed by the same letter do not differ significantly at 5\% level. The error bar represents the standard error. (*** indicates significant at $0.1 \%$ level. Capital and small letters indicate the rice bund and rice plot in different landscapes respectively.)

412 Fig. 5: Abundance of carabid beetles (CDB) in three rice landscapes. Means followed by the 413 same letter do not differ significantly at 5\% level. The error bar represents the standard error. $414 \quad(* * *$ indicates significant at $0.1 \%$, level. Capital and small letters indicate the rice bund and rice plot in different landscapes respectively.)

416 Fig. 6: Abundance of staphylinid beetles (STPD) in three rice landscapes. Means followed by 417 the same letter do not differ significantly at 5\% level. The error bar represents the standard error. (* indicates significant at 5\% level. Capital and small letters indicate the rice bund and rice plot in different landscapes respectively. ns: non-significant at 5\% level.) 
421 Fig. 8: Empirical variograms in one direction for the RED spectral band of an LANDSAT 8 422 image of $30 \mathrm{~m}$ ground spatial distance per pixel, of 6 southern Bangladesh Unions, were 423 sampled for NE abundances.

\section{Reference}

425 Ahmed N, Islam Z, Hasan M, Kamal NQ, 2002. Effect of Some Commonly Used Insecticides on Yellow Stem Borer Egg Parasitoids in Bangladesh. Bangladesh J Entomol, 12, 37-46.

427 Ahmed N, Englund JE, I Åhman, Lieberg M, Johansson E, 2011. Perception of pesticide use by farmers and neighbours in two periurban areas. Sci. Total Environ, 412, 77-86.

BCPA (Bangladesh Crop Protection Association), 2013. List of Registered Agricultural, Bio

Bianchi, F., Booij, C.J.H., Tscharntke, T., 2006. Sustainable pest regulation in agricultural landscapes: a review on landscape composition, biodiversity and natural pest control. Proceedings of the Royal Society B: Biological Sciences 273, 1715-1727.

Chien HV, Cuong L, 2009. Farms that apply insecticides for leaf folder control are 10 times more at risk to hopperburn. Available: http://ricehoppers.net/2009/09/farms-that -applyinsecticides-for-leaf-folder-control-are-10-times-more-at-risk-to-hopperburn/. Accessed 13

Sept 2009.

Duveiller G, Defourny P (2010) A conceptual framework to define the spatial resolution requirements for agricultural monitoring using remote sensing. Remote Sens Environ 114:2637-2650.

Hershey, R.R., 2000. Modeling the spatial distribution of ten tree species in Pennsylvania. In: 
445 Hassan ASMR, Bakshi K, 2005. Pest Management, productivity and environment: A 446 comparative study of IPM and conventional farmers of Northern Districts of Bangladesh. Pak $447 \quad$ J Soc Sci, 3, 1007-1014.

448 Heong KL, 2011. Ecological Engineering - a strategy to restore biodiversity and ecosystem 449 services for pest management in rice production. Technical Innovation 11. 450 http://www.spipm.cgiar.org/c/

451 Heong KL, 2010. Assessing BPH outbreak risks of commonly used insecticides. Available: 452 http://ricehoppers.net/2010/09/farmers-in-central-thailand-remain-trapped-by-the-bph453 problem/. Accessed 30 Sept 2010.

454 Heong KL, 2009. Planthopper outbreaks in 2009. Available: http://ricehoppers.net/2009/09/. 455 Accessed 25 Sept 2009.

456 Heong KL, Schoenly KG, 1998. Impact of insecticides on herbivore-natural enemy 457 communities in tropical rice ecosystems. In: Haskell PT, McEwen P, editors. Ecotoxicology: 458 Pesticides and Beneficial Organisms. Chapman and Hall, London, UK. 381-403.

459 IRRI, 2014. International Rice Research Institute, Philippines 460 (http://ricestat.irri.org:8080/wrs2/entrypoint.htm) accessed on 8 December 2014.

461 Islam Z, Haque SS, 2009. Rice planthopper outbreaks in Bangladesh. Available: 462 http://ricehoppers.net/2009/08/rice-planthopper-outbreaks-in-bangladesh/planthopper463 outbreaks-in-2009. Accessed 20 Aug 2009.

464 Islam Z, Hossain M, Chancellor T, Ahmed N, Hasan M, Haq M, 2010. Organic Rice465 Cropping in Bangladesh: Is it a Sustainable Alternative to Conventional Practice! J Environ 466 Sci Nat Res, 3, 233-238. 
468 Luecha M, 2010. Farmers' insecticide selections might have made their farms vulnerable to

469 hopperburn in Chainat, Thailand. Available:

470 http://ricehoppers.net/2010/01/farmers\%e2\%80\%99. Accessed 17 Jan 2010.

471 Matsumura M, Sanada-Morimura S, 2010. Recent status of insecticide resistance in Asian

472 rice planthoppers. JARQ 44, 225-230. doi: 10.6090/jarq.44.225

473 Moni 2011. BPH continues to threaten Thai rice farmers - heavy losses expected. Available:

474 http://ricehoppers.net/2011/04/bph-continues-to-threaten-thai-rice-farmers heavy-losses475 expected/. Accessed 20 April 2011.

476 Moni 2012. Planthopper problems intensify in Thailand's rice bowl. Available:

477 http://ricehoppers.net/2012/03/planthopper-problems-intensify-in-thailands-rice-bowl/.

$478 \quad$ Accessed 21 March 2012.

479 Rahaman MM, Islam KS, Jahan M, Mamun MAA, 2014. Relative abundance of stem borer

480 species and natural enemies in rice ecosystem at Madhupur, Tangail, Bangladesh. J Bangl

481 Agril Univ, 12, 267-272.

482

483 Shaw, D. R. and Willers, J. L. 2006. Improving pest management with remote sensing.

484 Outlooks on Pest Mgt. 17(5): 197-201.

485

486 Sigsgaard L, 2000. Early season natural biological control of insect pests in rice by 487 spiders - and some factors in the management of the cropping system that may affect this 488 control. In: European Arachnology. Ed. by Toft S, Scharff N, pp. 57-64.

490 Soitong K, Sriratanasak W, 2012. Will planthoppers continue to threaten Thailand's rice 491 production in 2012? Rice Department, Bangkok, Thailand. Available: 
492 http://ricehoppers.net/2012/02/will-planthopper-continue-to-threaten-thailands-rice-

493 production-in-2012/. Accessed 13 Feb 2012.

494 Stein, A., van der Meer, F., and Gorte, B, (eds). 2002. Spatial statistics for remote sensing.

495 Kluwer Academic Publishers, Dordrecht, Boston, London.

496 Stern V M, Smith RF, Van Den Bosch R, Hagen KS. 1959. The integrated control concept.

497 Hilgardia, 29, 81-101.

498 Teo C, 2011. Insecticide abuse in rice production causes planthopper outbreaks. Available:

499 http://www.asianscientist.com/topnews/irri-ban-insecticides-rice-production-due-to-

500 planthopper-outbreaks-2011/. Accessed 21 Dec 2011.

501 Travisi CM, Nijkamp P, Vindigni G, 2006. Pesticide risk valuation in empirical economics: a 502 comparative approach. Ecol Econ, 56, 455-74.

503 Wang L, Hui C, Sandhu HS, Li Z, Zhao Z, 2015. Population abundance and associated 504 factors of cereal aphids and armyworms under global change. Sci Rep 5, 18801; doi: $505 \quad 10.1038 /$ srep18801.

506 Werling, B.P., Meehan, T.D., Robertson, B.A., Gratton, C., Landis, D.A., 2011. Biocontrol 507 Potential Varies with Changes in Biofuel-Crop Plant Communities and Landscape 508 Perenniality. GCB Bioenergy. doi:10.1111/j.1757-1707.2011.01092.x.

509 Willers, J. L., Jenkins, J. N., Ladner, W. L., Gerard, P. D., Boykin, D. L., Hood, K. B., 510 McKibben, P. L., Samson, S. A., and Bethel, M. M. 2005. Site-specific approaches to cotton 511 insect control. Sampling and remote sensing techniques. Prec. Agric. 6: 431-452.

512 Woltza JM, Isaacsb, R, Landisa DA, 2012. Landscape structure and habitat management 513 differentially influence insect natural enemies in an agricultural landscape. Agricul Ecosyst 514 Environ, 152, 40- 49. 
515 Zhaofei Wen, Wu Shengjun, Liu Feng, Zhang Shuqing, Dale Patricia (2013) Variogram

516 Analysis for Assessing Landscape Spatial Heterogeneity in NDVI: an Example Applied to

517 Agriculture in the Jiansanjiang Reclamation area, Northeast China. Advances in Intelligent

518 Systems Research. doi:10.2991/rsete.2013.122

519

520

521

522 Fig. 1: Map of the Southern part of Bangladesh, for the Barisal Division, where six unions contained the three landscape categories (see text for listing) sampled for insects, while all

524 eighteen unions were employed for variography analyses.

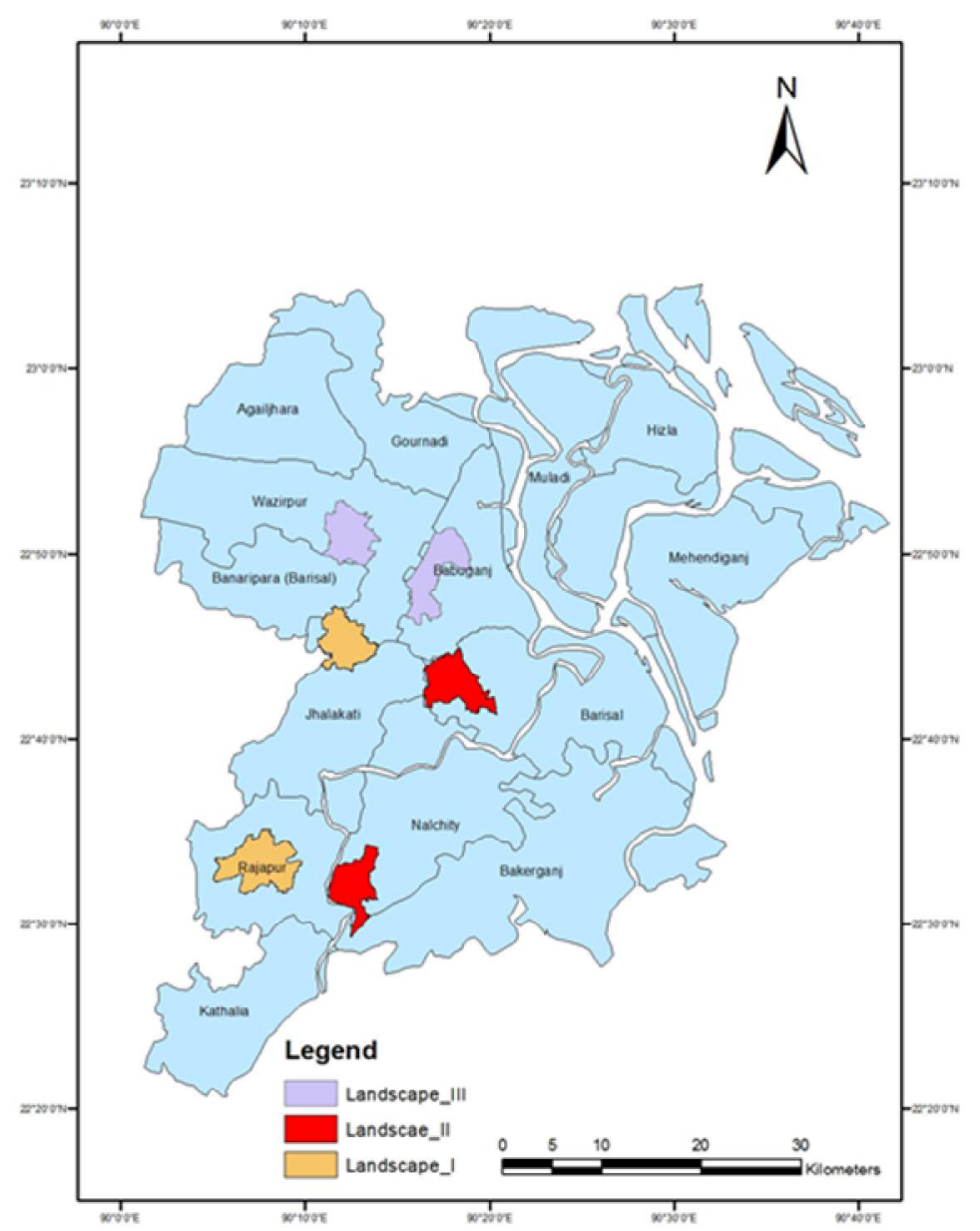


526 Fig. 2: Abundance of spider in three rice landscapes. Means followed by the same letter do 527 not differ significantly at $5 \%$ level. The error bar represents the standard error. $(* * *, * *$ and $*$ 528 indicate significant at $0.1 \%, 1 \%$ and $5 \%$ level respectively. Capital and small letters indicate 529 the rice bund and rice plot in different landscapes respectively.)

530

531

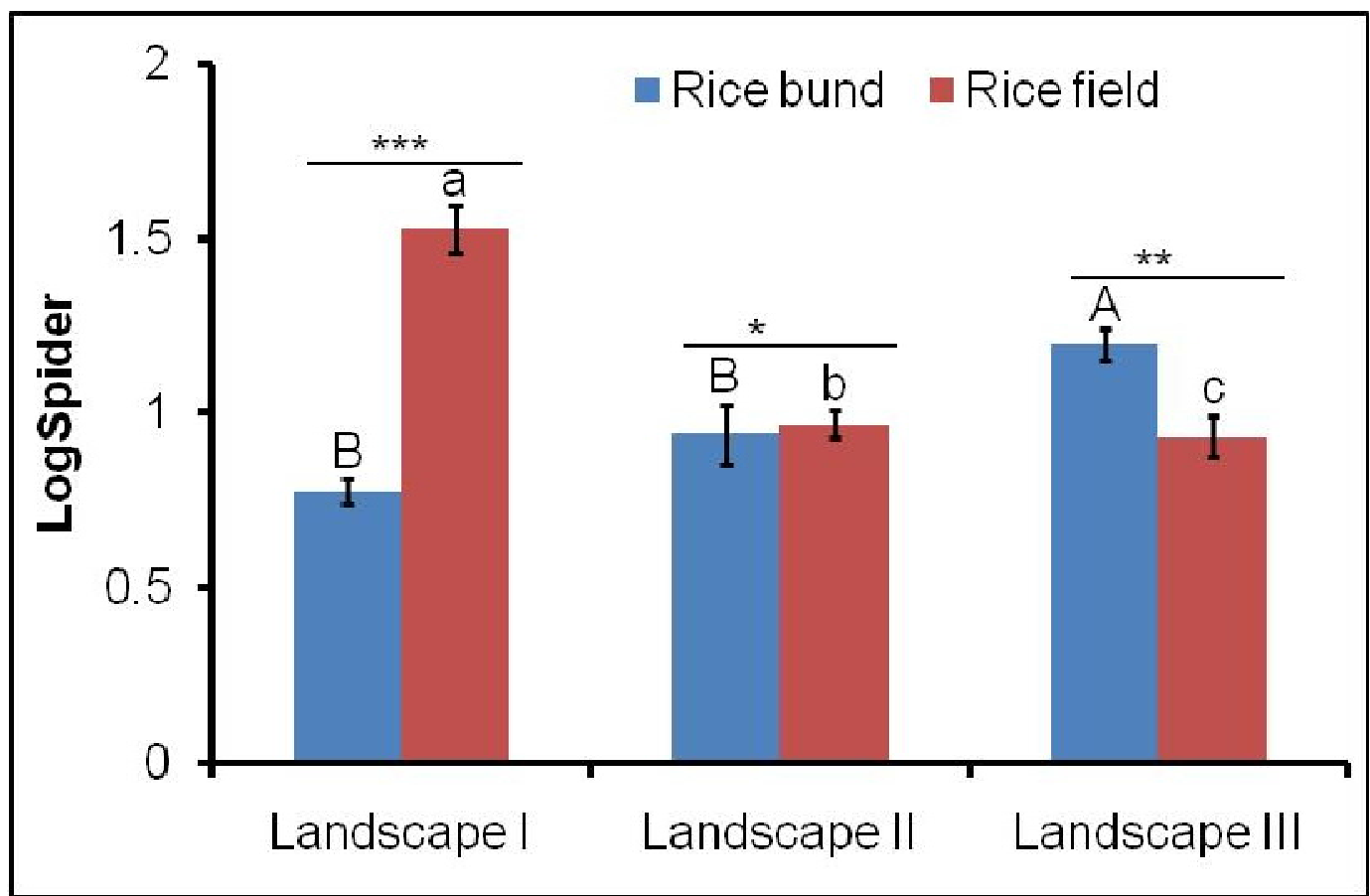

532

533

534

535

536

537 
539 Fig. 3: Effect of rice bund width on the spider individuals. Ten complete sweeps were used to 540 record population from rice bund.

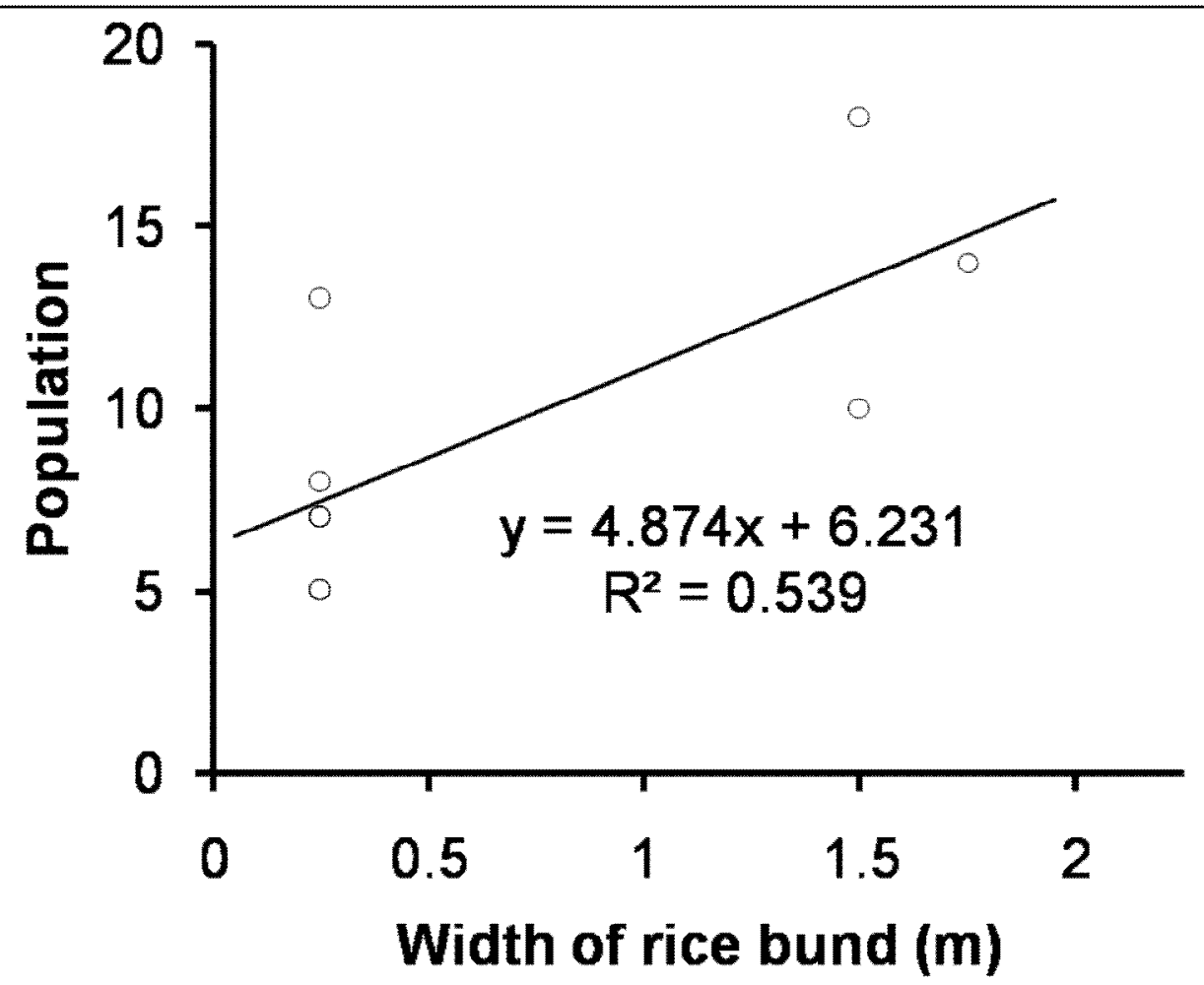

542

543

544

545

546

547

548

549 
551 Fig. 4: Abundance of green mirid bug (GMB) in three rice landscapes. Means followed by

552 the same letter do not differ significantly at 5\% level. The error bar represents the standard

553 error. (*** indicates significant at $0.1 \%$ level. Capital and small letters indicate the rice bund

554 and rice plot in different landscapes respectively.)

555

556

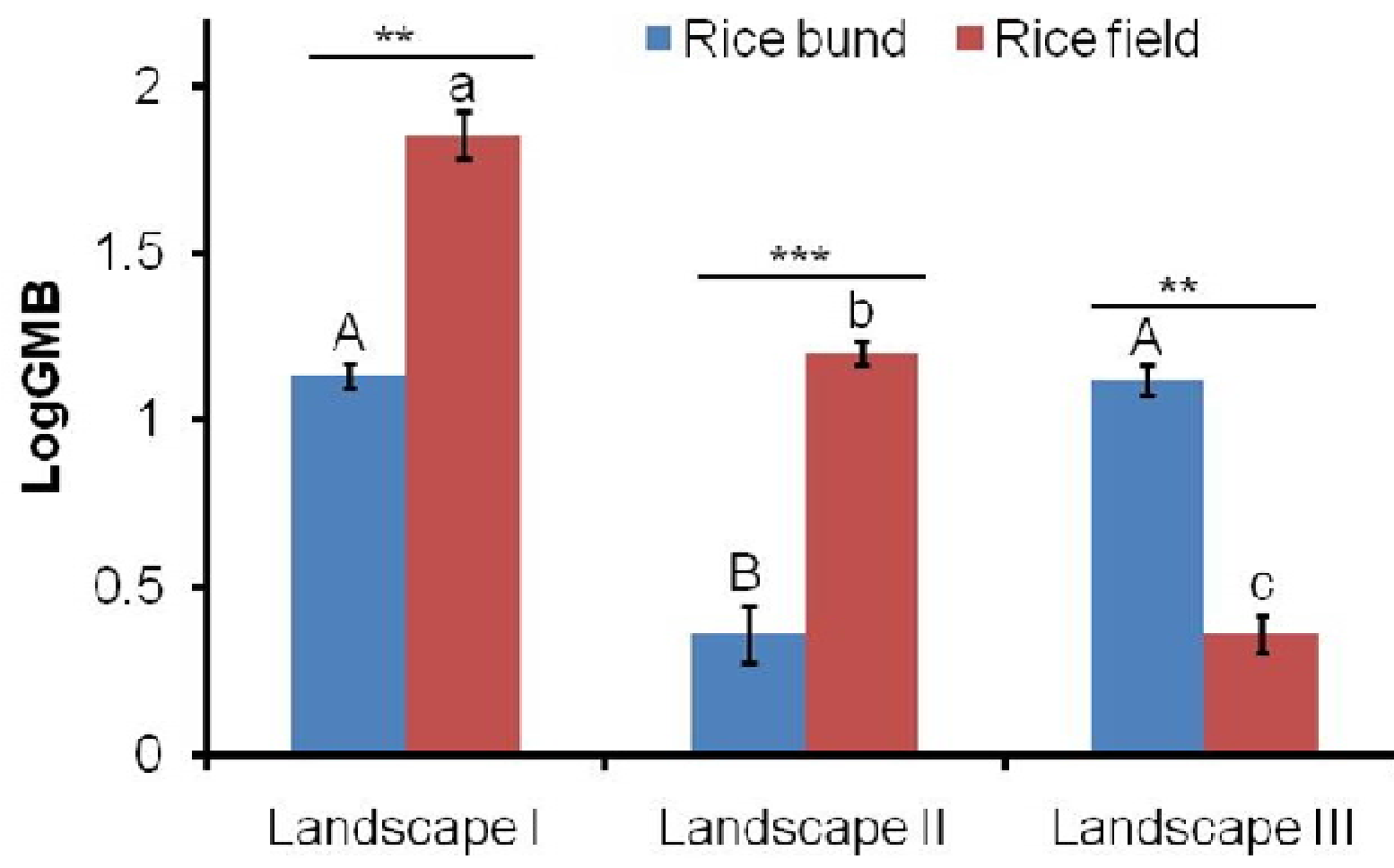


564 Fig. 5: Abundance of carabid beetles (CDB) in three rice landscapes. Means followed by the 565 same letter do not differ significantly at 5\% level. The error bar represents the standard error. 566 (*** indicates significant at $0.1 \%$, level. Capital and small letters indicate the rice bund and 567 rice plot in different landscapes respectively.)

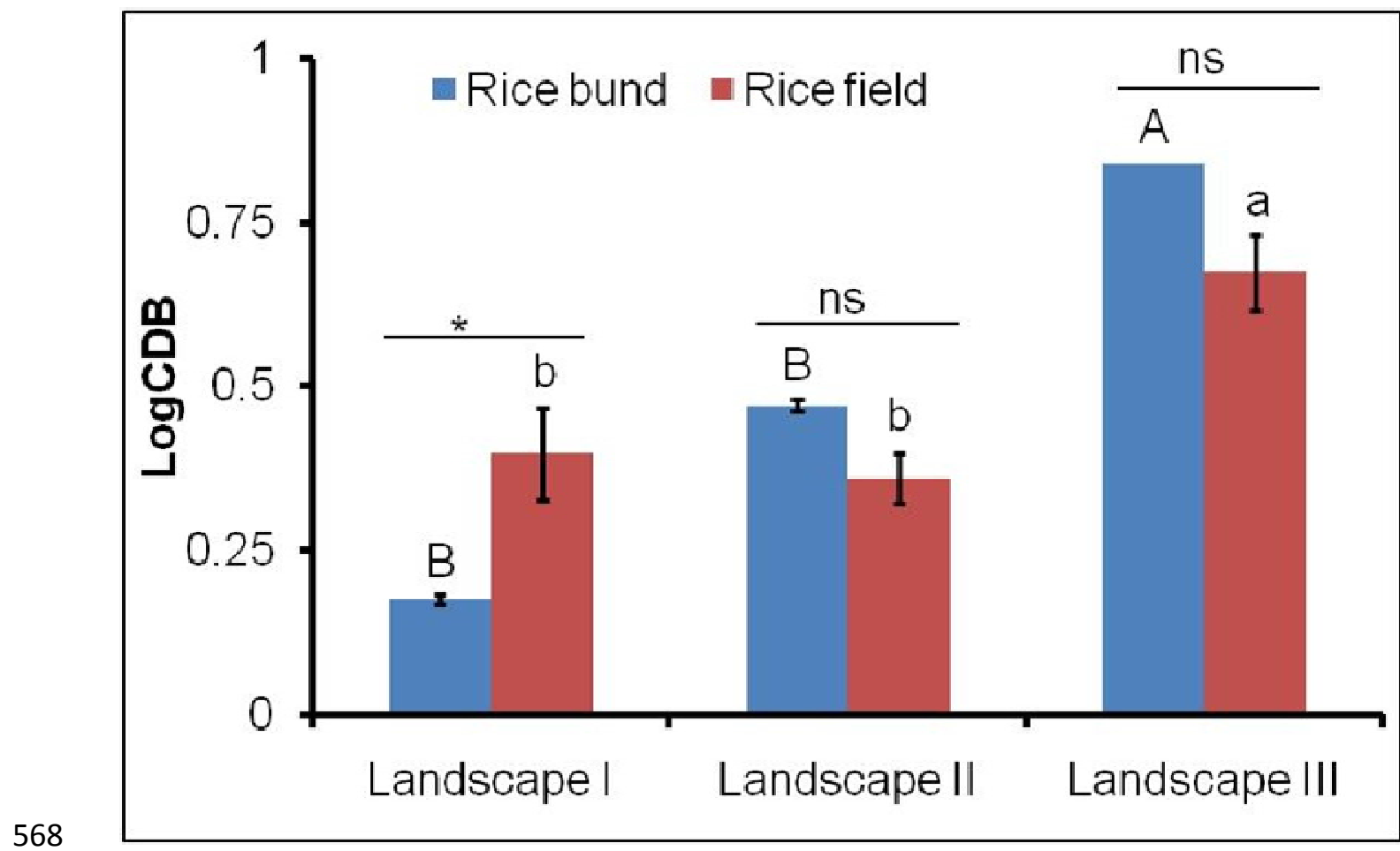

569

570

571

572

573

574

575 
577 Fig. 6: Abundance of staphylinid beetles (STPD) in three rice landscapes. Means followed by 578 the same letter do not differ significantly at 5\% level. The error bar represents the standard 579 error. (* indicates significant at 5\% level. Capital and small letters indicate the rice bund and 580 rice plot in different landscapes respectively. ns: non-significant at 5\% level.)

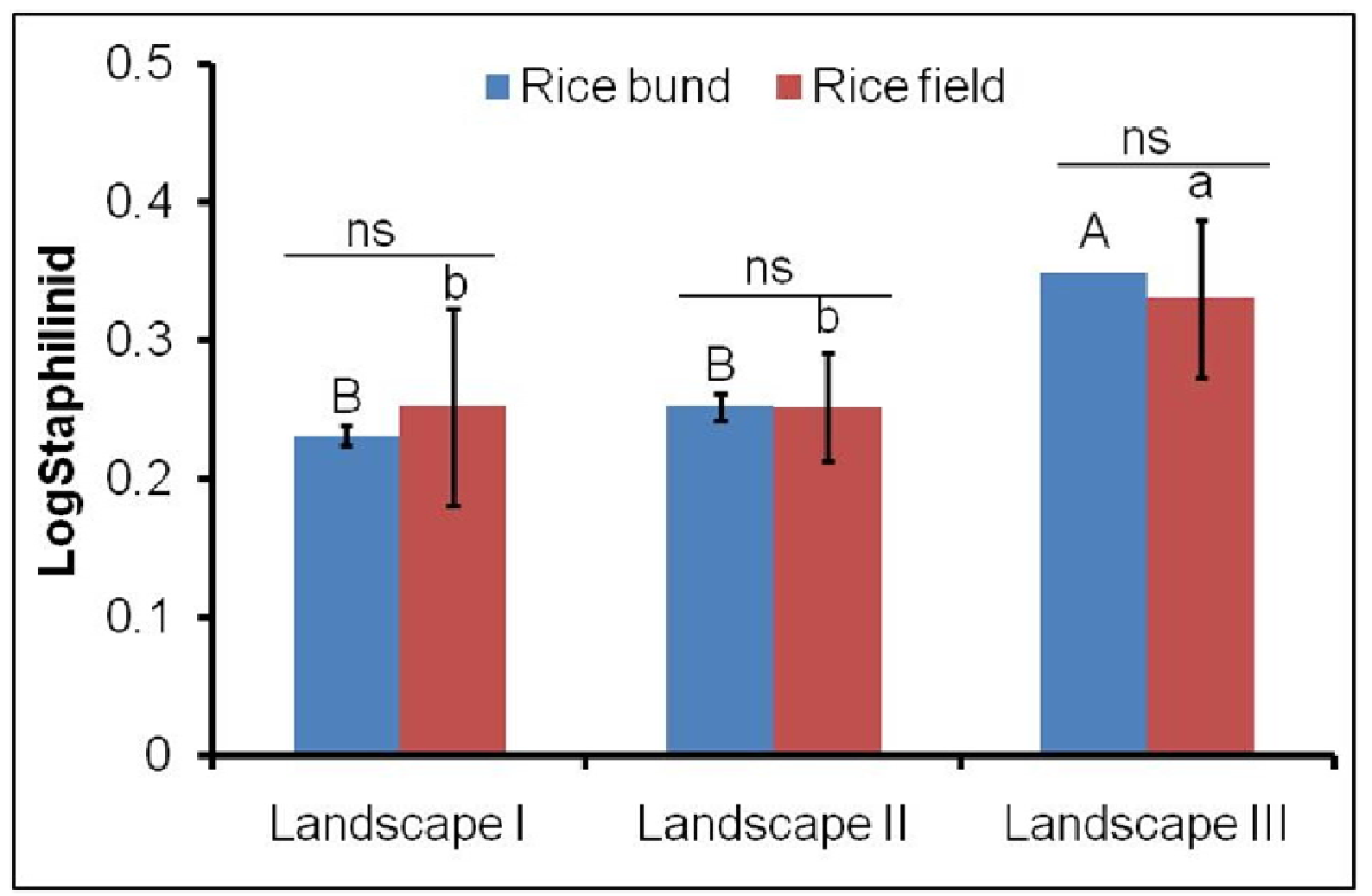

582 
590 Fig. 7: Relative abundance of four predators in three rice landscapes.

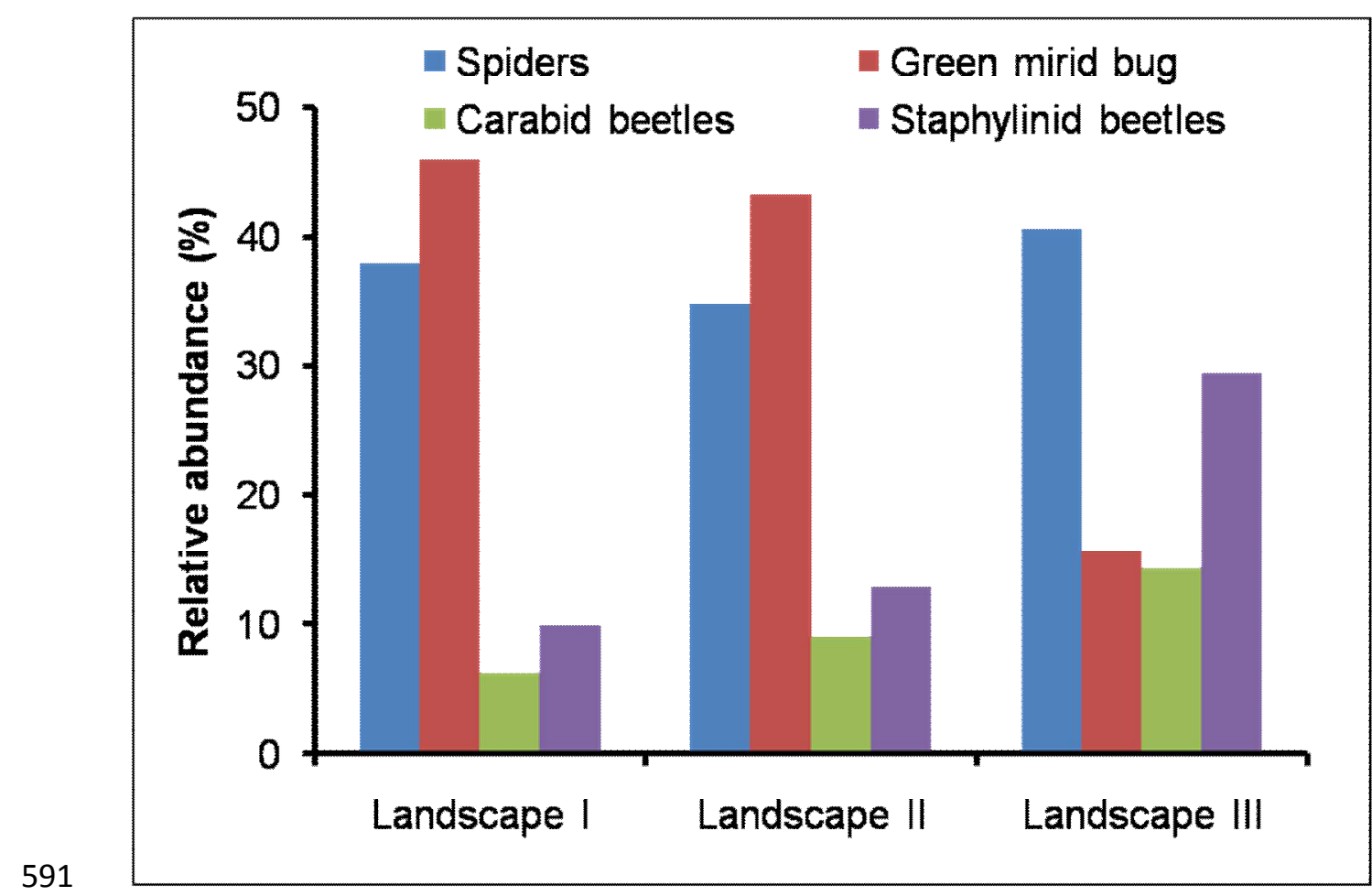

592

593

594

595

596

597

598

599

600 
601 Fig. 8: Empirical variograms in four directions for the RED spectral band of an LANDSAT 8 602 image of $30 \mathrm{~m}$ ground spatial distance per pixel, of 6 southern Bangladesh Unions, which 603 were sampled for NE abundances.
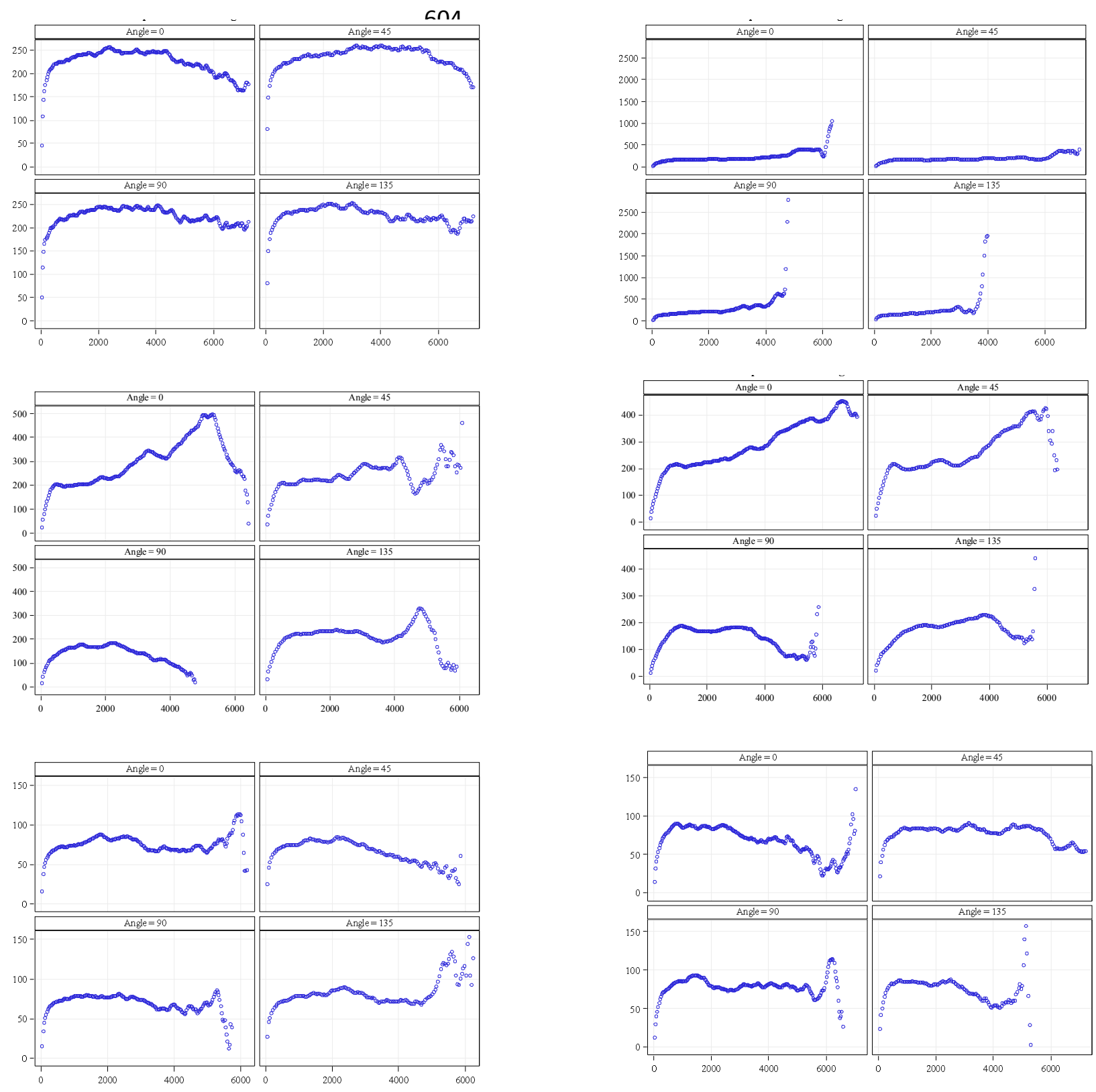